\title{
FILOSOFIA NA ESCOLA
}

Joana D'Arc Beserra dos Santos

\section{Márcia Pereira da Silva}

O presente texto tem por objetivo apresentar o Projeto Filosofia na Escola e falar um pouco sobre nossas experiências enquanto mediadoras do Projeto e sua importância para a formação do pedagogo.

\section{HISTÓRICO}

O Projeto Filosofia na Escola teve como semente embrionária a organização de um minicurso de extensão em 1996, por iniciativa dos professores da Universidade de Brasília (UnB), com o intuito de fomentar o debate sobre o tema na Capital Federal.

Em 1997, objetivando criar condições que favorecessem a implementação da Filosofia para Crianças em escolas públicas no Distrito Federal, os professores Walter Kohan e Ana Miriam Wunsch realizam uma série de atividades (palestras, oficinas, projeção de vídeos), entre elas destacamos a participação na "Semana Universitária da UnB" e na jornada "A Filosofia na Educação das Crianças", que contou a participação de professores das escolas pública e privada do DF e alunos da UnB.

O interesse demonstrado pela comunidade em relação ao tema motiva os Departamentos de Filosofia e de Teorias e Fundamentos da UnB a empreender esforços conjuntos para viabilizar a implantação de um projeto de extensão na rede pública de ensino do Distrito Federal.

Foram organizadas oficinas para a divulgação do projeto e muitos professores demonstraram interesse em participar. Inicialmente mais de 30 escolas e 140 professores se candidataram. Quatro escolas foram selecionadas em função de sua localização e do número de professores interessados.

Após a realização do curso de formação, foram definidas as equipes que atuariam junto às escolas. Estes grupos de trabalhos eram formados por coordenadores (composta de professores da UnB), por mediadores (estudantes de filosofia, pedagogia e psicologia da Universidade) e professores de ensino fundamental e médio da Fundação Educacional do Distrito Federal (FEDF).

Em 1998, tem-se efetivamente início as atividades do Projeto Filosofia na Escola nos estabelecimentos de ensino.

Nesse momento, com caráter experimental programou-se a realização de atividades práticas semanais e encontros regulares (semanais e mensais) destinados à reflexão, ao planejamento e avaliação, bem como, ao aprofundamento teórico. 
Em 1999, Brasilia sediou o Congresso Internacional de Filosofia com Crianças e Jovens - X congresso do ICPIC (Internacional Council of Philosophical Inquiry with children), realizado no período de 4 a 9 de julho, onde estiveram presentes 1300 pessoas vindas dos 5 continentes. $O$ projeto participou ativamente da organização e das atividades do evento.

Em 2001, foi organizado o primeiro Curso de Especialização sobre Ensino de Filosofia nos níveis Fundamental e Médio com 50 vagas e 24 professores de oito países e de diversas partes do Brasil, envolvidos na condução dos diferentes módulos e orientação dos trabalhos finais.

A Universidade de Brasília passou a ofertar Estágio e duas disciplinas na área de Filosofia na Escola: Comunidade de Investigação Filosófica e Filosofia para crianças.

Daquela semente até nossos dias o projeto enfrentou diversos obstáculos, sofreu alterações, mas consolidou-se como espaço fundamental para o ensino de Filosofia.

O projeto que foi inicialmente inspirado na experiência de Mathew Lipman, em 1970 , com crianças da $5^{\mathrm{a}}$ série, procurou galgar outros caminhos, traçar novos horizontes e expandir sua atuação. Hoje, desenvolvemos as atividades em sete escolas da rede pública das diferentes regiões administrativas do Distrito Federal (Sobradinho, Planaltina, Ceilândia, Plano Piloto e Paranoá), e contamos com o envolvimento de quatro professores universitários; 60 alunos universitários de diferentes cursos (Pedagogia, Filosofia, Psicologia, Antropologia e Artes Plásticas); 80 professores da rede pública (da Educação Infantil e dos Ensinos Fundamental e Médio); e mais de 2000 estudantes entre crianças, jovens e adultos.

Por ser um projeto de extensão permanente, o curso de formação é aberto a todos os interessados (alunos universitários, professores das escolas públicas e membros da comunidade). O curso é organizado pelos professores da Área de Filosofia na Escola da Faculdade de Educação da Universidade de Brasília, tem uma carga horária de 120 horas, distribuídas entre atividades na universidade e nas escolas.

Essa carga horária é dividida da seguinte forma: curso de formação com duração de 18 horas; planejamento e avaliação - 2 horas semanais; atividades práticas -2 horas semanais; reunião geral - 03 horas mensais. Há ainda um horário reservado para a elaboração dos relatórios e do trabalho final.

\section{O PROJETO NA PRÁTICA}

Para que você tenha uma visão mais abrangente de todo o processo de desenvolvimento do projeto, faremos uma breve descrição dos diferentes momentos que compõem esta iniciativa. 
O curso de formação é o momento destinado à realização de oficinas temáticas, onde são discutidos os pressupostos que fundamentam a prática do Projeto Filosofia na Escola.

O planejamento das atividades ocorre em cada escola, é o momento destinado à reflexão, avaliação das atividades, bem como, discussão, planejamento $e$ aprofundamento teórico. Por não possuir um modelo rígido a ser seguido, cada grupo possui autonomia para criar uma dinâmica própria de atuação.

É nas atividades práticas que professores, mediadores e alunos encontram-se, com o objetivo de aprofundar seus conhecimentos e ampliar seus horizontes a partir da reflexão, da problematização e da curiosidade.

A reunião geral acontece na universidade, no último sábado de cada mês. Ocasião em que coordenadores, professores e mediadores se encontram com o propósito de trocar experiências, refletir sobre a prática filosófica.

O grupo de estudos ocorre todas as terças e quintas-feiras à noite. Mediadores e professores reúnem-se com os coordenadores para discutir diferentes textos, buscando relacioná-los com a prática, orientando-a e fundamentando-a.

Coordenadores, professores e mediadores elaboram relatórios individuais sobre as formas como estão percebendo as atividades práticas, suas expectativas e inquietações. Cada relatório é composto de duas partes: uma descritiva e outra reflexiva, onde é possível aprofundar-se em questões que se tornaram significativas.

O trabalho final constitui-se de uma reflexão individual sobre a atuação no decorrer do processo. É a oportunidade que cada envolvido tem de descrever suas experiências e apresentar suas perspectivas para o futuro. Ambos os documentos tornam-se parte do arquivo do Projeto Filosofia na Escola que está disponível a todos os interessados na sala do projeto, na Faculdade de Educação da Universidade de Brasilia.

Com caráter informativo, foi criada uma página eletrônica:

http://www.unb.br/fe/tef/filoesco. Neste endereço é possível conhecer um pouco sobre o projeto. Temos ainda, uma lista eletrônica de discussão onde todos os interessados podem associar-se a fim de estar contribuindo com idéias e participando das discussões, além de se informar sobre os eventos na área.

Buscando criar espaços de reflexão sobre os vários fenômenos sociais que envolvem a Filosofia e o pensar filosófico, os coordenadores do Projeto Filosofia na Escola em conjunto com a Educatio Consultoria Jr. Em Educação, estão organizando o III Fórum Centro-Oeste sobre o Ensino de Filosofia - "Filosofia, Educação e Política" que acontecerá nos dia 20,21e 22 de novembro de 2003, na Faculdade de Educação da Universidade de Brasília, e terá como objetivo abordar as dimensões políticas, pedagógicas e filosóficas do ensino de Filosofia. O evento contará com a participação de conceituados palestrantes nas 
áreas de Filosofia e Educação e estará aberto a toda a comunidade de estudantes, educadores, filósofos, pedagogos, psicólogos e demais interessados na temática.

\section{ALGUNS SENTIDOS DO PROJETO}

Compreendemos que não existe apenas uma Filosofia, mas várias formas de pensá-la e de praticá-la. No projeto Filosofia na Escola tal como o desenvolvemos, procuramos entendê-la como uma experiência de pensamento, um movimento do pensar que atravessa a vida de quem a pratica (Kohan, 2000:10)

No entanto, não basta afirmar que estamos levando a Filosofia às crianças, jovens e adultos envolvidos no projeto. É preciso apresentar algumas idéias que possam contribuir para o entendimento da filosofia como a praticamos.

Certamente, não se trata de oferecer um marco teórico fechado. Ao contrário, essa atividade requer o exercício de questionar constantemente os nossos valores, saberes e idéias; de esforçar-se permanentemente por elucidar, debater e avaliar os pressupostos e implicações de nossa atuação.

É do conhecimento de todos os rumos que tomou a educação no Brasil. Reprodutivista, servindo apenas de instrumento de inculcação de ideologias burguesas para adequação do indivíduo às exigências de uma sociedade desigual e injusta.

$\mathrm{Na}$ escola convencionou-se chamar ensino-aprendizagem, um processo linear e unilateral, no qual um sujeito ensina e o outro aprende. Ensinar significa possibilitar que os alunos assimilem os conteúdos curriculares e desenvolvam habilidades e competências que lhes permitam o bom desempenho escolar.

Porém mudanças políticas, sociais, econômicas e tecnológicas ocorridas nas últimas décadas têm exigido da educação uma nova postura, voltada para formar o cidadão, o sujeito integral (social, cognitivo, afetivo, ético).

Nessa perspectiva, a escola apresenta-se como espaço ideal para o diálogo, o entrosamento, a curiosidade e a dúvida. Paulo Freire afirma: "Formar é muito mais do que puramente treinar o educando no desempenho de destrezas" (1996, p. 15). Portanto educar é ir além das convenções pedagógicas que se encerram na avaliação dos conhecimentos.

É nesse contexto que o projeto Filosofia na Escola se propõe a trabalhar na rede pública de ensino, por acreditar que a Filosofia seja um meio pelo qual, vozes silenciadas por uma sociedade excludente, possam finalmente ser ouvidas.

Entendemos o espaço público como espaço comum, ou seja, aquele que não está - ou pelo menos não deveria estar - submetido a interesses particulares.

A proposta do Projeto vai de encontro com essa tendência, pois atribui ao aluno um papel ativo no processo de aprendizagem, cabendo-lhe questionar, debater, pesquisar, comparar, deduzir, argumentar e transformar o que é dado como certo $e$ 
verdadeiro. É importante ressaltar que as atividades implicam num caminhar juntos a um destino desconhecido e inesperado. Não temos como objetivo a transmissão de conceitos seculares, socialmente estabelecidos. O que propomos é uma reflexão sobre esses conceitos; como, por que e para quê foram criados.

A atividade filosófica não demanda avaliação do desempenho individual, uma vez que não implica necessariamente na aquisição de novos conceitos, mas na problematização dos conhecimentos adquiridos, por meio da reflexão coletiva. Esse exercício não tem por objetivo chegar a um fim consensual, mas despertar o interesse pelas coisas que interferem no cotidiano de cada individuo, levando-o a posicionar-se diante do mundo.

Por isso nossa ação pauta-se fundamentalmente no diálogo. Dialogar é conviver com a diferença. É através desse procedimento que conhecemos um mundo mais diversificado. Precisamos ouvir outras vozes, conhecer o diferente, o novo, o estranho. É por meio do diálogo que compartilhamos emoções, sentimentos e inquietações.

O diálogo filosófico não é uma situação ideal onde seres harmoniosos estabelecem uma comunicação e chegam a um fim comum, mas afirma-se em situações imperfeitas do discurso como o mal-entendido e o desacordo.

O mal-entendido se afirma na imprecisão das palavras, no equívoco . O desacordo se estabelece quanto ao sentido que damos as palavras. Podemos usar as mesmas palavras para afirmar coisas diferentes. Entendemos que o diálogo filosófico é o espaço de explicitação e compreensão dos desacordos. (Kohan, 2000:35)

Outra questão importante é o sentido que damos a experiência. Quando falamos em experiência, logo relacionamos a experimento, laboratório, comprovação. Contudo a filosofia que praticamos no Projeto Filosofia na Escola é uma experiência do pensamento que comporta um rumo incerto, um destino indeterminado. Como uma experiência intransferível $e$ individual não visa a reprodução, mas uma transformação das formas como vivemos e como nos relacionamos com o mundo. Nesse sentido é algo imprevisível. Não é possível antecipar quando e como acontecerá. (Kohan 2000:30)

Os encontros sejam eles entre coordenadores, professores, mediadores e alunos, em geral são muito intensos, envolvem uma gama de sensações que levam cada indivíduo, a seu modo, despir-se de suas crenças mais arraigadas, olhar-se e buscar problematizar a vida e o mundo que nos envolve. Para que isso ocorra é necessário que haja um clima amistoso entre os integrantes do grupo.

As relações de amizade que se estabelecem favorecem a discussão, à medida que nos sentimos valorizados, confiantes e livres para expor nossos pensamentos sem medo da reprovação, da crítica e do julgamento.

Todas essas ações são importantes por entendermos o indivíduo em sua totalidade: físico, cognitivo, afetivo, social, moral e cultural. 
É nessa perspectiva que procuramos desenvolver o projeto na Casa de Lívia/Lar Fabiano de Cristo (LFC), instituição filantrópica, sem fins lucrativos, que atende a uma clientela em situação de extrema pobreza, em sua maioria, moradores do Condomínio Arapoanga, um dos setores mais violentos do Distrito Federal.

As atividades do Projeto nesta instituição, tiveram início em março de 2003 e é desenvolvido com um grupo de adolescentes do sexo feminino. São trinta meninas com idade entre 12 e 16 anos, todas matriculadas na rede oficial de ensino. $\mathrm{O}$ grupo de trabalho é composto de oito mediadoras, uma monitora da instituição e uma coordenadora.

Os encontros ocorrem na instituição, nas sextas-feiras, com duração de duas horas e mais duas para avaliação, reflexão e planejamento do próximo encontro.

As atividades são instigantes por oferecer-nos a possibilidade de apreciar outras realidades, outros pontos de vista e por aproximarmo-nos de outros pensamentos e conhecê-los melhor.

Gostaríamos de lembrar que a dinâmica tende a favorecer a participação, mas cada aluna está livre para escolher como e quando contribuir na discussão. Pois acreditamos que o silêncio pode ser produtivo.

Cada grupo possui autonomia para atuar conforme a dinâmica da turma, portanto este relato é apenas mais um dentre tantos e poderia estar sendo descrito $e$ interpretado de diversas formas, assim sendo, reflete a nossa forma particular de entender o trabalho que desenvolvemos no LFC.

Destacamos algumas dificuldades que sentimos junto ao grupo. A primeira dificuldade deu-se pela desconfiança do grupo em relação a nossos objetivos. Por vezes fomos sabatinadas quanto a nossa proposta, nossos objetivos e até nossa metodologia. Para superar precisávamos criar um ambiente amistoso que favorecesse a criação de vínculos, de laços de amizade e confiança.

Em segundo lugar, precisávamos romper com o mito da padronização, onde todos devem pensar igual. Nos propomos a pensar juntos, o que é diferente, pois ao final, cada um tirará suas próprias conclusões, que serão respeitadas e levadas em conta para o direcionamento das discussões. Uma frase de Ranciere representa bem o sentido que damos ao "caminhar juntos":

"Quem busca, sempre encontra, não encontra necessariamente aquilo que buscava, menos ainda, aquilo que é preciso encontrar. Mas encontra alguma coisa nova, a relacionar à coisa que já conhece." (2002, p 57).

A terceira dificuldade com a qual nos deparamos refere-se ao modelo escolar, aquele que transmite o conhecimento acabado, único e verdadeiro. $O$ fato de não termos respostas prontas incomodava as meninas, que não entendiam o sentido de buscar algo que possivelmente já estaria concluído. 
Além das inquietações das adolescentes, também precisamos lidar com nossas inquietações, responder nossas perguntas e encontrar solução para nossos problemas. É nesse aspecto que o grupo de estudos e as reuniões gerais entram para fornecer o suporte teórico-metodológico de que necessitamos. Essas questões mais que desafios, são vivências a serem compartilhadas com os demais participantes, que podem contribuir significativamente na superação dos problemas.

Dessa forma não estamos sozinhos nesta iniciativa, mas podemos nos comparar a pequenas células, que unidas formam um corpo complexo e eficaz.

Qual a relevância desse trabalho na formação do pedagogo?

A prática pedagógica fundamenta-se na convicção de que à escola não cabe apenas transmitir conhecimentos que habilitem o educando para uma posição de relevo no mercado de trabalho, mas também - e como pressuposto fundamental preparar seus estudantes para o exercício pleno da cidadania, como agentes de transformação dotados do espírito crítico e consciente. Nesse sentido entendemos o espírito crítico como uma inquietação constante com as certezas do mundo e da vida. É preciso estar sempre questionando os valores e sentidos que damos as coisas e como nos relacionamos com nossos atos.

Em todos os âmbitos da vida social, a educação desponta como a coluna vertebral das relações entre pessoas e grupos constituindo garantia única e preservação de qualquer intento de democratização. Não é papel da filosofia definir os rumos das transformações, defendendo uma ou outra posição, mas motivar a reflexão sobre os modos de pensar e agir adquiridos, para que as pessoas possam pensar por si mesmas e decidir com os outros as transformações desejadas, pensando nas conseqüências e possibilidades.

A Filosofia - enquanto pensar dialógico, crítico e problematizador - assume uma postura transformadora do papel da escola e da própria educação. As reflexões experienciadas no Projeto Filosofia na Escola influenciaram sensivelmente nossa maneira de perceber o mundo. O grande desafio é fazer com que tais mudanças subjetivas contribuam cada vez mais para transformar a escola em um espaço no qual a problematização de suas práticas e das questões que a atravessam seja uma realidade.

Bibliografia:

RANCIÈRE, Jacques. O mestre ignorante - cinco lições sobre a emancipação 2002.

intelectual. Tradução de Lílian do Valle - Belo Horizonte : Autêntica,

KOHAN, Walter Omar - LEAL, Bernardina - RIBEIRO, Álvaro (orgs) (2000)

Filosofia na escola pública. Petrópolis : Vozes. 
FREIRE, Paulo. Pedagogia da autonomia: saberes necessários à prática educativa

São Paulo : Paz e Terra, 1996. (Coleção Leitura) 